\title{
Consumo de água e produção de grãos do feijoeiro irrigado em sistemas plantio direto e convencional
}

\author{
Water consumption and grains production by irrigated beans in no tillage and conventional systems
}

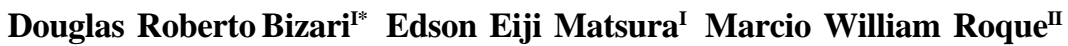 \\ Anderson Luiz de Souza ${ }^{\text {III }}$
}

RESUMO

O uso inadequado dos recursos hídricos na agricultura, em busca de elevadas produtividades, tem causado impactos negativos nas reservas de água, diminuindo a eficiência dos sistemas produtivos irrigados. O objetivo deste trabalho foi determinar o consumo de água por meio dos coeficientes de cultura para o feijoeiro irrigado por aspersão, nos diversos estádios de seu desenvolvimento, mais a produção de grãos e seus componentes, em sistema plantio direto $e$ convencional. O manejo da irrigação foi realizado por tensiômetros, para manter o conteúdo de água no solo entre 28 (momento de irrigar) e 31\% (capacidade de campo). A evapotranspiração da cultura (ETC) foi determinada pelo balanço hídrico a campo, e a evapotranspiração de referência foi (ETo) calculada pelo método de Penman-Monteith, sendo utilizados os dados climáticos obtidos junto à Estação Meteorológica instalada na área experimental. Os resultados indicam que os coeficientes de cultura do feijoeiro nos estádios de florescimento e enchimento de grãos, em sistema plantio direto, apresentam os menores valores quando comparado ao sistema convencional. As plantas do feijoeiro no sistema plantio direto são mais eficientes no uso da água, pelo fato de apresentarem, nesse sistema, maior produtividade de grãos com menor consumo de água.

Palavras-chave: Phaseolus vulgaris, sistemas de manejo do solo, coeficiente de cultura, eficiência no uso da água

\section{ABSTRACT}

The inappropriate use of water resources in agriculture, to get higher yields, has caused negative impacts on soil water storage, reducing the efficiency of irrigated productive systems. The aim of this research was to study water use through crop coefficients for sprinkler-irrigated beans at different development stages, in addition to the production of grains and their components, in no tillage and tillage crop systems. Irrigation management was monitored with tensiometers to maintain the soil water content level between 28\% (at the moment of irrigation) and 31\% (field capacity). The crop evapotranspiration level (ETc) was obtained from the soil water balance and the reference evapotranspiration (ETo) using the Penman-Monteith method. The results indicate that bean crop coefficients show lower values in the no tillage system than in the conventional tillage system, during flowering and pod formation stages. The bean plants in no tillage system are more efficient in relation to water use than the conventional tillage system, because in this system, the bean crop shows higher grain yield with lower water consumption.

Key words: Phaseolus vulgaris, soil tillage systems, crop coefficient, water use efficiency.

\section{INTRODUÇÃO}

O uso inadequado dos recursos hídricos na agricultura visando a altas produtividades é um dos fatores que tem contribuído para seu desperdício, com consequências indesejáveis ao meio ambiente. Nesse contexto, é fundamental, nos dias de hoje, a adoção de técnicas racionais de manejo conservacionista do solo e da água para a sustentabilidade na agricultura, de forma que possam ser mantidos, ao longo do tempo, esses recursos com quantidades e qualidades suficientes para a manutenção de níveis satisfatórios de produtividade (WUTKE et al., 2000).

\footnotetext{
IConselho Integrado de Planejamento e Gestão, Área de concentração em Água e Solos, Faculdade de Engenharia Agrícola Universidade Estadual de Campinas (UNICAMP), Cidade Universitária Zeferino Vaz, Campinas, SP, Brasil. E-mail: douglas.bizari@feagri.unicamp.br.*Autor para correspondência.

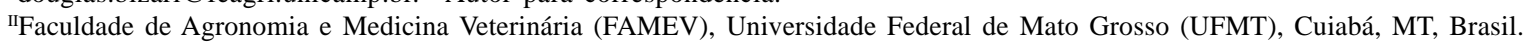

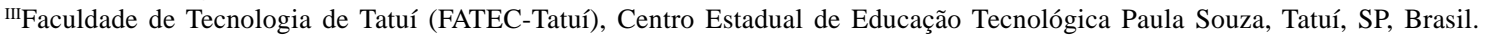


Uma maneira de a agricultura irrigada ganhar mais eficiência no uso da água é por meio da utilização do sistema plantio direto. Essa técnica tem seu fundamento na mínima mobilização do solo, na manutenção da cobertura morta que permanece sobre sua superfície e na rotação de culturas. A cobertura morta atua como agente isolante, impedindo oscilações bruscas da temperatura do solo e contribuindo para a menor evaporação da água armazenada com melhor aproveitamento do conteúdo de água no solo pelas plantas.

As plantas do feijoeiro são pouco tolerantes ao déficit hídrico, podendo haver queda significativa de produtividade se este ocorrer nos estádios de florescimento e enchimento de grãos, em virtude de sua baixa capacidade de recuperação após o estresse hídrico e do seu sistema radicular pouco desenvolvido (MOUHOUCHE et al., 1998).

Em trabalho realizado por STONE (2005) com a cultura do feijoeiro irrigado em sistemas plantio direto e convencional, em Guairá, (SP), foram encontrados valores do consumo de água pela cultura de $254 \mathrm{~mm}$ e 343mm, respectivamente, mostrando a importância do sistema plantio direto na diminuição do número de irrigações e no aumento da disponibilidade de água para as plantas nesse sistema.

Em regiões em que, durante uma parte do ano, as condições de temperatura e de radiação solar são suficientes para a produção agrícola, mas existe déficit hídrico significativo, como nas regiões Norte, Nordeste e Noroeste do Estado de São Paulo, a adoção de técnicas conjugadas de sistema plantio direto e irrigação tem se mostrado promissora, sob o ponto de vista de melhor exploração do solo e também pelo aspecto conservacionista. O objetivo do trabalho é determinar os coeficientes de cultura $(\mathrm{Kc})$ e a produção de grãos e seus componentes na cultura do feijoeiro irrigado, em sistemas plantio direto (SPD) e convencional (SC).

\section{MATERIAL E MÉTODOS}

O trabalho foi desenvolvido em um Latossolo Vermelho Distroférrico típico, em Campinas, $\mathrm{SP}$, cujas coordenadas geográficas são: latitude $22^{\circ}$ 48'57'sul, longitude 4703'33” oeste e altitude média de 640m. Após a colheita do milho (cultura de verão), realizou-se no SPD uma pulverização com o herbicida glifosate na dose de $4 \mathrm{~L} \mathrm{ha}^{-1}$, enquanto que, na parcela sob SC, foram realizadas somente duas gradagens, sendo uma pesada e a outra leve. Instalou-se a cultura do feijoeiro em duas parcelas coletoras com $600 \mathrm{~m}^{2}$ de área útil cada, em SPD (8,7Mg ha-1 de palhada de milho) e SC (2,3Mg ha ${ }^{-1}$ de palhada de milho), quantidades provenientes da cultura de verão e dos tratos culturais empregados para a implantação da cultura de inverno. As parcelas estudadas são independentes devido ao tipo de manejo diferenciado que vem sendo realizado em cada uma delas desde a safra de 2003.

Foi utilizada no ensaio a variedade Carioca Precoce, semeada no dia 24/06/2006, com espaçamento de $0,45 \mathrm{~m}$ entre linhas e densidade de plantio de 10 plantas por metro linear. As análises química e granulométrica do solo no SPD apresentaram os seguintes resultados: $\mathrm{pH}\left(\mathrm{CaCL}_{2}\right), 5,0 ; \mathrm{Ca}^{2+}: 54,0 \mathrm{mmol}_{c}$ $\mathrm{dm}^{-3} ; \mathrm{Mg}^{2+}: 23,0 \mathrm{mmol}_{\mathrm{c}} \mathrm{dm}^{-3} ; \mathrm{P}: 44,0 \mathrm{mg} \mathrm{dm}^{-3} ; \mathrm{K}^{2}$ 7,0 $\mathrm{mmol}_{\mathrm{c}}$ $\mathrm{dm}^{-3}$; areia: $310 \mathrm{~g} \mathrm{~kg}^{-1}$; silte: $158 \mathrm{~g} \mathrm{~kg}^{-1}$ e argila: $532 \mathrm{~g} \mathrm{~kg}^{-1}$. Para o SC, os resultados das análises foram: $\mathrm{pH}\left(\mathrm{CaCL}_{2}\right)$, 5,5; $\mathrm{Ca}^{2+}: 47,0 \mathrm{mmol}_{\mathrm{c}} \mathrm{dm}^{-3} ; \mathrm{Mg}^{2+}: 14,0 \mathrm{mmol}_{\mathrm{c}} \mathrm{dm}^{-3} ; \mathrm{P}$ : $39,0 \mathrm{mg} \mathrm{dm}^{-3}$; K: $4,5 \mathrm{mmol}_{\mathrm{c}} \mathrm{dm}^{-3}$; areia: $224 \mathrm{~g} \mathrm{~kg}^{-1}$; silte: $202 \mathrm{~g} \mathrm{~kg}^{-1}$ e argila: $574 \mathrm{~g} \mathrm{~kg}^{-1}$. A adubação básica foi realizada com base nas informações contidas na análise de solo, sendo utilizados $300 \mathrm{~kg} \mathrm{ha}^{-1}$ da formulação 0416-04 para os dois sistemas de manejo. Aplicou-se a quantidade de $120 \mathrm{~kg} \mathrm{ha}^{-1}$ de sulfato de amônia na adubação nitrogenada de cobertura, parcelada aos 30 e 60 dias após a emergência das plantas, segundo recomendação de AMBROSANO et al. (1996).

O sistema de irrigação empregado era constituído por aspersores de modelo Naan 5022, com vazão de $0,82 \mathrm{~m}^{3} \mathrm{~h}^{-1}$ para uma pressão de $1,5 \mathrm{kgf} \mathrm{cm}^{-2}$, raio molhado de $11 \mathrm{~m}$ e intensidade de precipitação média de $7,6 \mathrm{~mm} \mathrm{~h}^{-1}$. Para determinar o momento da irrigação e seu controle, adotou-se a recomendação de SILVEIRA \& STONE (2002) para a cultura do feijoeiro. O sistema de irrigação proporcionou uma precipitação média de $6 \mathrm{~mm} \mathrm{~h}^{-1}$, determinada pela quantificação do volume de água em 176 coletores (malha $2 \mathrm{~m}$ x $2 \mathrm{~m}$ ) por parcela durante a avaliação do Coeficiente de Uniformidade de Christiansen (CUC).

A Evapotranspiração da cultura do feijoeiro (ETc) foi calculada no período de 12 a 79 dias após a emergência (D.A.E.) por meio do balanço hídrico de campo, considerando-se a profundidade do solo de $0,2 \mathrm{~m}$, e em quatro estádios da cultura do feijoeiro:

$$
E t_{c}=P+I \pm D-R-\Delta h
$$

em que: $E_{c}$ é a evapotranspiração da cultura [mm], Pé a precipitação pluviométrica expressa em [mm], I é a irrigação [mm], D é a drenagem ou ascensão capilar [mm], R é o escoamento superficial [mm] e $\Delta$ h é a variação do armazenamento de água no solo [mm].

A precipitação e a irrigação foram registradas por pluviômetro e hidrômetros, respectivamente, instalados nas parcelas experimentais. A variação do armazenamento de água foi determinada pela diferença entre os conteúdos de 
água no solo, obtidos por meio das leituras diárias nos tensiômetros, utilizando-se a curva de retenção de água no solo para a camada de $0-0,20 \mathrm{~m}$ de profundidade. A partir da curva de retenção de água no solo, esta foi ajustada ao modelo de VAN GENUTCHEN (1980), utilizando-se o programa desenvolvido por DOURADO NETO et al. (2000):

$$
\theta=\theta \text { res }+\frac{(\theta \text { sat }-\theta \text { res })}{\left(1+(\partial+h)^{n}\right)^{m}}
$$

em que: $\theta$ é o conteúdo volumétrico de água no solo $\left[\mathrm{cm}^{3} \mathrm{~cm}^{-3}\right]$, Ores é o conteúdo volumétrico residual de água no solo $\left[\mathrm{cm}^{3} \mathrm{~cm}^{-3}\right]$, $\theta$ sat é o conteúdo volumétrico saturado de água no solo $\left[\mathrm{cm}^{3} \mathrm{~cm}^{-3}\right]$, h é o potencial matricial da água no solo [kPa], n e m $(\mathrm{m}=1-1 / \mathrm{n})$ são parâmetros empíricos adimensionais de ajuste; e $\partial$ é um parâmetro empírico de ajuste $\left[\mathrm{kPa}^{-1}\right]$. Os valores dos parâmetros de ajuste usados para o SPD foram: Ores $=0,253 \mathrm{~cm}^{3} \mathrm{~cm}^{-3}, \theta \mathrm{sat}=0,421 \mathrm{~cm}^{3} \mathrm{~cm}^{-3},\left(=1,7089 \mathrm{kPa}^{-1}\right.$, $\mathrm{n}=13,1612$, e $\mathrm{m}=0,0253$. Para o SC, os valores utilizados foram: $\theta$ res $=0,242 \mathrm{~cm}^{3} \mathrm{~cm}^{-3}, \theta$ sat $=0,454 \mathrm{~cm}^{3} \mathrm{~cm}^{-3}, \partial=1,6826$ $\mathrm{kPa}-1, \mathrm{n}=13,6906$ e m=0,0298. A drenagem profunda e a ascensão capilar da água no solo foram calculadas pela equação de Buckingham - Darcy:

$$
q z=-k(\theta) * \frac{\mathrm{d} \phi}{\mathrm{dz}}
$$

em que: qz é a densidade de fluxo da água no solo [mm dia $\left.^{-1}\right], K(\theta)$ é a condutividade hidráulica do solo em função do conteúdo volumétrico de água no solo [mm $\left.\mathrm{dia}^{-1}\right]$ e $\mathrm{d} \Phi / \mathrm{dz}$ é o gradiente de potencial total da água do solo $\left[\mathrm{m} \mathrm{m}^{-1}\right]$. A condutividade hidráulica do solo $K(\theta)$ foi determinada por meio da equação 4 proposta por LOYOLA\& \&REVEDELLO(2003). Acondutividade hidráulica saturada (Ks) foi obtida a campo, usando o Permeâmetro de Guelph.

$$
k(\theta)=k_{s}\left[\frac{\left(\theta-\theta_{\text {res }}\right)}{\left(\theta_{\text {sat }}-\theta_{\text {res }}\right)}\right]^{0,5} *\left\{1-\left[1-\left[\frac{\left(\theta-\theta_{\text {res }}\right)}{\theta_{\text {sat }}-\theta_{\text {res }}}\right]^{1 / m}\right]^{m}\right\}
$$

Para os dois sistemas de manejo do solo, os valores de drenagem e ascensão capilar foram considerados nulos em razão dos baixos valores verificados. O componente escoamento superficial foi desconsiderado em virtude da dificuldade de sua determinação no momento das precipitações e da não ocorrência deste nas irrigações.

$\mathrm{Na}$ área experimental, foi instalada uma estação meteorológica automática, marca Campbell Scientific, composta dos sensores de: temperatura do ar, umidade relativa do ar, radiação solar, velocidade e direção do vento e precipitação pluviométrica. A partir dos dados coletados, determinou-se a Evapotranspiração de referência (ETo), calculada pela equação de Penman-Monteith modificada pela FAO (ALLEN et al., 1998). A ETo faz parte da programação da própria estação:

$$
E T_{0}=\frac{0,408 \Delta\left(R_{n}-G\right)+\gamma\left(\frac{900}{T+273}\right) U_{2}\left(e_{s}-e_{a}\right)}{\Delta+\gamma\left(1+0,34 U_{2}\right)}
$$

em que: ETo é a evapotranspiração da cultura de referência [mm dia $\left.{ }^{-1}\right]$, Rn é a radiação líquida na superfície da cultura [ $\mathrm{MJ} \mathrm{m}^{-2} \mathrm{dia}^{-1}$ ], G é o fluxo de calor do solo [MJ $\mathrm{m}^{-2} \mathrm{dia}^{-1}$, $\mathrm{T}$ a temperatura média do ar $\left[{ }^{\circ} \mathrm{C}\right], \mathrm{U}_{2}$ é a velocidade do vento medida a $2 \mathrm{~m}$ de altura $\left[\mathrm{m} \mathrm{s}^{-1}\right]$, (esea) é o déficit de pressão de vapor $[\mathrm{kPa}], \Delta$ é a declividade da curva de pressão de vapor $\left[\mathrm{kPa}^{\circ} \mathrm{C}^{-1}\right]$, $\gamma$ é a constante psicrométrica $\left[\mathrm{kPa}^{\circ} \mathrm{C}^{-1}\right]$, e 900 é o fator de conversão. A radiação liquida $(\mathrm{Rn})$ foi calculada por meio da diferença entre a radiação de ondas curtas e longas, utilizando-se as equações descritas por ALLEN et al. (1998) e citadas por MEDEIROS (2002). Com relação ao fluxo de calor no solo (G), o boletim da FAO 56, que foi adotado neste trabalho, recomenda, que para períodos diários, (G) possa ser desprezado.

Pela relação entre a ETo e a ETc, foram determinados os coeficientes de cultura (Kc) nos seguintes estádios fenológicos do feijoeiro: desenvolvimento vegetativo (DV), florescimento (FL), enchimento de grãos (EG) e maturação fisiológica (MF). Para a determinação da produção de grãos e seus componentes, foram coletadas três linhas de plantas dentro da mesma parcela coletora, caracterizando as repetições de plantas para os dois sistemas de manejo estudados, nas quais foram avaliados: a população de plantas por linha (PL), o número de vagens por planta (NV), o número de grãos por vagem (NG) e o índice de colheita (IC). Os resultados obtidos na avaliação dos componentes da produção foram analisados usando o programa Minitab 12, por meio do teste T, com intervalo de confiança de 95 \%. Foi determinada a eficiência do uso da água (EUA) pela relação entre a produtividade de grãos obtida em toda a parcela e a ETc.

\section{RESULTADOS E DISCUSSÃO}

As lâminas totais de água aportadas à cultura do feijoeiro foram de 224,4mm e 261,3mm para o SPD e $\mathrm{SC}$, respectivamente. Isso significa que o SPD proporcionou uma economia de água em torno de $14 \%$. STONE \& MOREIRA (2000) constataram economia de 14 a 30\% no consumo de água pelas plantas do feijoeiro nesse mesmo sistema. Maior economia de água decorrente da utilização da palhada no solo, no sistema de manejo conservacionista, também foi verificada por ANDRADE et al. (2002) e STONE (2005). Na tabela 1 e figura 1, respectivamente, são apresentados os valores 
Tabela 1 - Valores médios de evapotrans piração da cultura (ETc), evapotranspiração de referência (ETo) e coeficiente de cultura (Kc) nos sistemas plantio direto e convencional para cada estádio da cultura do feijoeiro.

\begin{tabular}{|c|c|c|c|c|c|c|}
\hline \multirow[b]{3}{*}{ DAE } & \multirow[b]{3}{*}{ Estádio } & \multirow[b]{3}{*}{ ETo $\mathrm{mm} \mathrm{dia}^{-1}$} & \multicolumn{4}{|c|}{ 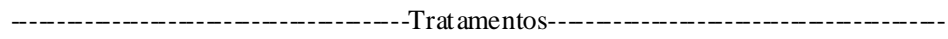 } \\
\hline & & & \multicolumn{2}{|c|}{--------sistema plantio di reto-------- } & \multicolumn{2}{|c|}{--------s istema convencional-------- } \\
\hline & & & ETc mm dia ${ }^{-1}$ & Kc & ETc mm dia ${ }^{-1}$ & Kc \\
\hline 12 a 35 & DV & 2,46 & 1,74 & 0,79 & 1,76 & 0,79 \\
\hline 36 a 56 & FL & 4,67 & 4,31 & 0,88 & 5,72 & 1,18 \\
\hline 57 a 70 & EG & 5,10 & 5,43 & 1,11 & 6,21 & 1,24 \\
\hline 71 a 79 & $\mathrm{MF}$ & 4,71 & 5,30 & 1,13 & 5,42 & 1,15 \\
\hline
\end{tabular}

DAE - Di as após em ergência.

DV - desenvolvimento vegetativo; FL - florescimento; EG - enchimento de grãos; MF - mat uração fisiológica.

médios de ETc, ETo e Kc por intervalos de dias após emergência das plantas (D.A.E.) e os acumulados de ETo e ETc nos dois sistemas de manejo do solo. A ETc do feijoeiro em SPD foi de 223,5mm, enquanto que no SC o consumo foi de $260,6 \mathrm{~mm}$, com os maiores valores obtidos por este último a partir do estádio de FL da cultura até a MF. Para a ETo, o valor foi de $237 \mathrm{~mm}$. No estádio de DV, os valores encontrados de ETc foram bem semelhantes para os dois sistemas de manejo do solo, em torno de $1,75 \mathrm{~mm} \mathrm{dia}^{-1}$, atingindo o valor máximo de 5,43mm dia ${ }^{-1}$ no estádio de EG, no SPD, e de 6,21mm dia $^{-1}$ no SC. Na MF, a ETc decresceu, sendo registrados $5,30 \mathrm{~mm} \mathrm{dia}^{-1}$ e $5,42 \mathrm{~mm} \mathrm{dia}{ }^{-1}$ para SPD e SC, respectivamente.
Os valores médios de Kc determinados para os dois sistemas de manejo estudados foram de 0,79 no DV, evidenciando praticamente as mesmas necessidades de água pelas plantas nos dois tratamentos (Tabela 1). JUNQUEIRA et al. (2004) encontraram praticamente os mesmos valores para a cultura do feijoeiro no mesmo estádio de desenvolvimento e nos mesmos sistemas de preparo, com valores de Kc entre 0,7 e 0,8. Isso mostra que a cobertura morta não teve efeito no consumo de água pela planta no início de seu desenvolvimento, que é característico da sua fisiologia e não do sistema em que a cultura é instalada. As plantas no SPD apresentaram menores valores médios de Kc nos

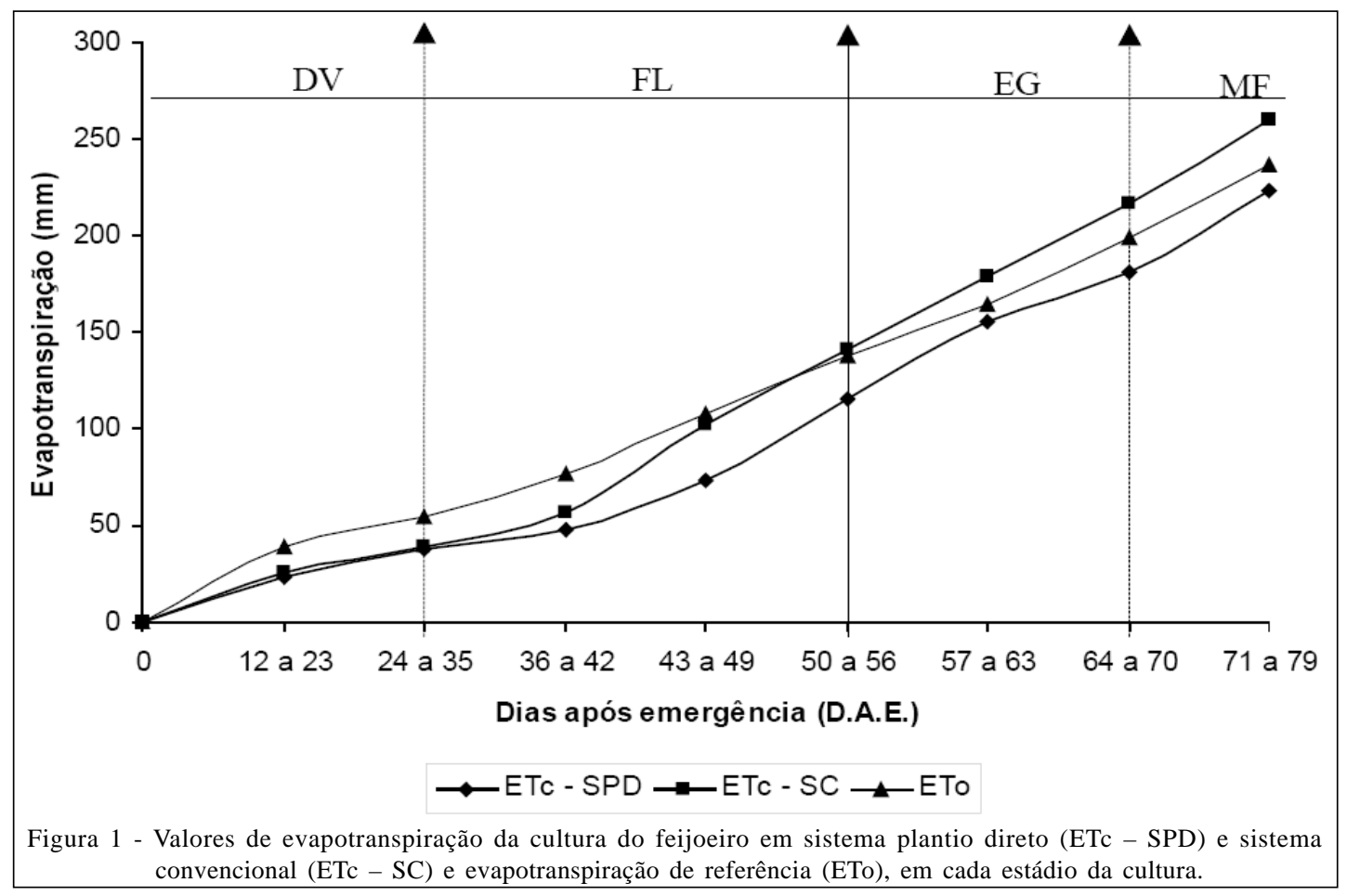

Ciência Rural, v.39, n.7, out, 2009. 
estádios de FL e EG (0,88 e 1,11), em comparação ao SC $(1,18$ e 1,24), propiciando economia de água de $46 \%$ e 31\%. JUNQUEIRA et al. (2004), trabalhando com o feijoeiro comum irrigado no SC, encontraram no FL/EG valores de Kc variando de 1,05 a 1,21. Esses valores representam um consumo de água pelas plantas $16 \mathrm{e}$ $8 \%$ superiores aos obtidos pelas plantas do SPD do presente ensaio, nesse mesmo período. Nesse caso, observa-se que a cobertura morta começa a ter papel fundamental na economia de água, com maior disponibilidade de água para as plantas no estádio de FL/EG, na qual a exigência de águas pelas plantas é maior que nos demais estádios de desenvolvimento.

No estádio de MF, os valores médios de Kc foram praticamente iguais para as plantas em SPD e SC, com valores de 1,13 e 1,15, respectivamente. Esses altos valores encontrados na MF, provavelmente, se devem à ocorrência de precipitações que contribuíram para o aumento da ETc em função da não contabilização do escoamento superficial no balanço hídrico de campo, superestimando os valores encontrados. No entanto, JUNQUEIRA et al. (2004) encontraram menores valores de Kc nesse estádio, variando de 0,55 a 0,82 nos dois sistemas de preparo. Essa diminuição dos resultados obtidos de Kc encontrados pelos autores se deve ao início do processo de senescência das plantas e maturação dos grãos, havendo uma redução no consumo de água e consequentemente da irrigação.

Na avaliação dos componentes da produção (Tabela 2), os sistemas de manejo do solo não afetaram significamente esses parâmetros, exceto para o número de vagens (NV), que foi maior nas plantas do feijoeiro em SPD $(12,08)$, diferindo estatisticamente do SC $(8,44)$, com um incremento de três vagens por planta no primeiro. O número de grãos por vagem (NG) foi praticamente igual entre os dois sistemas de manejo do solo, com valores em torno de 4,0. Isso já era esperado, pois é uma característica da própria variedade, independentemente do sistema de cultivo ao qual as plantas sejam submetidas. Nesse caso, não houve diferença estatística significativa entre as duas populações de plantas avaliadas.

Para o componente número de plantas por linha (PL), os resultados obtidos foram de 164 e 169, para o SPD e SC, respectivamente, que corresponde a uma população final de plantas estimada em torno de 11.000 plantas por parcela. Isso se deve ao fato de que no momento da instalação da cultura, a plantadora foi regulada para semear 10 plantas por metro linear, propiciando praticamente as mesmas populações de plantas em cada parcela avaliada, garantindo-se assim um estande adequado para o presente ensaio. Como já era esperado, não foi verificada diferença significativa com relação a esse componente da produção nos dois sistemas de cultivo. Isso também ocorreu com o componente índice de colheita (IC), cujos valores obtidos pelas plantas ficaram acima de $60 \%$, ou seja, de toda a massa produzida pela planta, $60 \%$ desse valor foi encontrado na massa de grãos produzida pela planta. Esse resultado é semelhante ao observado por JUNQUEIRA et al. (2004) que encontraram valores em torno de $62 \%$ para a cultura do feijoeiro em SC.

Em trabalho realizado com a cultura do feijoeiro, variedade Pérola, em SPD,ANDRADE et al(2002) constataram que todos os componentes da produção não diferiram estatisticamente do tratamento sem cobertura do solo, com valores de NV variando de 9,6 a 13,2; NG de 5,4 a 6,6; e PF, de 10.800 a 12.300 , respectivamente. Neste caso, com relação ao NV e NG, os referidos autores encontraram um incremento em torno de uma vagem por planta e de dois a três grãos por vagem, em comparação com os valores obtidos no presente ensaio pelas plantas nos mesmos sistemas de manejo avaliados. Ao avaliar os componentes de produção do feijoeiro, variedade Imbabello “INIAP 404”, em SC, com diferentes lâminas de irrigação e níveis de fertilização, CALVACHE et al. (1997) constataram valores para NV de 15,5 a 24,1; NG de 3,9 a 4,5 e IC de 40 a 68\%. Para o NV, os valores obtidos pelos autores foram bem superiores aos encontrados no presente ensaio nos dois sistemas de preparo. Isso,

Tabela 2 - Dados médios ${ }^{1}$ de população de plantas por linha (PL), número de vagens por planta (NV), número de grãos por vagem (NG) e índice de colheita (IC) na cul tura do fei joeiro, em sist emas plantio direto e convencional.

\begin{tabular}{|c|c|c|c|c|c|c|c|c|}
\hline \multirow{3}{*}{ População de plantas nas parcelas } & \multicolumn{8}{|c|}{ 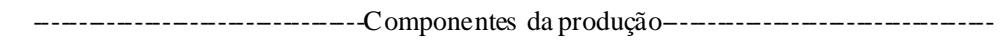 } \\
\hline & \multicolumn{2}{|c|}{-----PL----- } & \multicolumn{2}{|c|}{----NV----- } & \multicolumn{2}{|c|}{-----NG----- } & \multicolumn{2}{|c|}{----IC (\%)---- } \\
\hline & méd ia & $\mathrm{Dp}$ & média & $\mathrm{Dp}$ & média & Dp & Média & $\overline{\mathrm{Dp}}$ \\
\hline Plantas no Sistema plantio direto & $164,00^{\mathrm{a}}$ & 29,20 & $12,08^{\mathrm{a}}$ & 0,16 & $3,76^{\mathrm{a}}$ & 0,20 & $66,43^{\mathrm{a}}$ & 1,57 \\
\hline Plantas no Sistema convenci onal & $169,00^{\mathrm{a}}$ & 39,40 & $8,44^{b}$ & 1,08 & $3,54^{\mathrm{a}}$ & 0,10 & $64,50^{\mathrm{a}}$ & 2,09 \\
\hline
\end{tabular}

${ }^{1}$ Médi as com subscritos diferentes na vertical são estatis ticamente diferentes entre si pelo teste T, para um intervalo de confiança de $95 \%$. Dp: desvio padrão. 
provavelmente se deu em função do tipo de estudo, local do ensaio e por se tratar de uma outra variedade. No entanto, com relação ao NG os valores foram bem próximos aos obtidos no presente ensaio, que é em torno de quatro grãos por vagem. Para o IC, os resultados obtidos foram em torno de $20 \%$ superiores aos apresentados pelos autores mencionados anteriormente, cujo valor foi de $40 \%$ para esse componente de produção no tratamento com menor lâmina de irrigação. Para os demais tratamentos, o IC variou de 60 a $68 \%$, ou seja, valores semelhantes aos obtidos no presente ensaio.

A produtividade da cultura do feijoeiro em SPD foi de $2.337 \mathrm{~kg} \mathrm{ha}^{-1}$, superando em $36,2 \%$ à obtida em SC (1.492 $\left.\mathrm{kg} \mathrm{ha}^{-1}\right)$. O valor encontrado no primeiro foi $14 \%$ inferior ao encontrado por STONE \& MOREIRA (2000) para o feijoeiro no mesmo sistema. Os mesmos autores também encontraram os maiores valores também no SC com grade e arado de disco, em 38 e 34\%, respectivamente quando comparado ao SC do presente ensaio. Apesar disso, a produtividade das plantas em SPD do ensaio ficou próxima da produtividade média esperada para a variedade em estudo (2.500 $\left.\mathrm{kg} \mathrm{ha}^{-1}\right)$ e acima da média do Estado de São Paulo (1.650 $\mathrm{kg} \mathrm{ha}^{-1}$ ), segundo (IEA, 2007). Avaliando a produtividade da cultura do feijoeiro, ANDRADE et al (2002) encontraram valores de $2.718 \mathrm{~kg} \mathrm{ha}^{-1}$ a $2.937 \mathrm{~kg} \mathrm{ha}^{-1}$, com o maior valor obtido no SC. Esses valores também ficaram acima dos obtidos neste estudo, com um incremento de 15 e $50 \%$ em comparação com o SPD e SC, respectivamente. No estudo de produtividade e dos componentes da produção, os valores obtidos podem variar em função das características das variedades estudadas, dos sistemas de preparo do solo, do manejo da irrigação, da lâmina de água aplicada, dos tratos culturais, das ocorrências de pragas e das doenças, etc., além da variabilidade do solo que influencia diretamente os parâmetros avaliados.

Com relação à eficiência do uso da água (EUA), o valor obtido em SPD foi de 10,46kg ha-1 $\mathrm{mm}^{-1}$, proporcionando incremento de $45 \%$ em relação ao SC, com valor de $5,72 \mathrm{~kg} \mathrm{ha}^{-1} \mathrm{~mm}^{-1}$. Também foi verificado por ANDRADE et al., (2002) maior EUA pelo SPD mais cobertura morta no solo, com valores acima de 10,00kg $\mathrm{ha}^{-1} \mathrm{~mm}^{-1}$. Isso mostra a importância da cobertura morta no processo de diminuição da evaporação da água no solo e, consequentemente o aumento da disponibilidade de água para as plantas em comparação com o SC.

\section{CONCLUSÕES}

Os coeficientes de cultura das plantas do feijoeiro em SPD são menores que os encontrados no SC, nos estádios de florescimento e enchimento de grãos. A cultura do feijoeiro no SPD apresentou maior número de vagens por planta. Não foram verificadas diferenças estatísticas significativas entre os demais componentes da produção nos dois sistemas de manejo do solo. As plantas do feijoeiro no SPD são mais eficientes no uso da água que as cultivadas no SC.

\section{AGRADECIMENTOS}

À Fundação de Amparo à Pesquisa do Estado de São Paulo (FAPESP), pela concessão da bolsa de mestrado ao primeiro autor.

\section{REFERÊNCIAS}

ALLEN, R.G. et al. Crop evapotranspiration: guidelines for computing crop water requirements. Rome: FAO, 1998. 328p. (Irrigation and Drainage Paper, 56).

AMBROSANO, E.J. et al. Leguminosas e oleaginosas. In: RAIJ, B.V. et al. Recomendações de adubação e calagem do Estado de São Paulo. Campinas: Instituto Agronômico de Campinas, 1996. Cap.19, p.187-199.

ANDRADE, R.S. et al. Consumo relativo de água do feijoeiro no plantio direto em função da porcentagem de cobertura morta do solo. Revista Brasileira de Engenharia Agrícola e Ambiental, v.6, p.35-38, 2002. disponível em: <http://www.scielo.br/ scielo.ph p ? script =s ci_art text \& pid = S 1415 43662002000100007\&lng=en\&nrm=iso\&tlng=pt>. doi: 10.1590/ S1415-43662002000100007.

CALVACHE, A.M. et al. Efeito da deficiência hídrica e da adubação nitrogenada na produtividade e na eficiência do uso da água em uma cultura de feijão. Scientia Agrícola, v.54, p. 1-15, 1997. Disponível em: <http://www.scielo.br/scielo.php?script=sci_arttext\&pid=S010390161997000200019\&lng=en\&nrm=iso\&tlng=pt>. doi: 10.1590/ S0103-90161997000200019.

DOURADO NETO, D. et al. Software to model soil water retention curves (SWRC, version 2.0). Scientia Agricola, v.57, p.191-196, 2000. Disponível em: <http://www.scielo.br/scielo.php?pid=S010390162000000100031\&script=sci_arttext>. doi: 10.1590/S010390162000000100031.

IEA. INSTITUto DE ECONOMIA AgRÍCOlA. Previsões e Estimativas das Safras Agrícolas do Estado de São Paulo, Ano Agrícola 2006/07, São Paulo, 20 nov. 2007. Capturado em 20 nov. 2007. Online. Disponível na Internet: <http:// www.iea.sp.gov.br/out/producao/ps-1105-21-1.php>.

LOYOLA, J.M.T.; PREVEDELLO, C.L. Modelos analíticos para predição do processo da redistribuição da água no solo. Revista Brasileira de Ciência do Solo, v.27, p.783-787, 2003. Disponível em: <http:/www.scielo.br/scielo.php?script=sci_arttext\&pid=S010006832003000500002\&lng=en\&nrm=iso\&tlng=pt>. doi: 10.1590/ S0100-06832003000500002.

JUNQUEIRA, A.M. et al. Consumo de água pelo feijoeiro comum, cv. 'Carioca'. Revista Brasileira de Agrometeorologia, v.12, p.51-56, 2004.

MEDEIROS, A.T. Estimativa da evapotranspiração de referência a partir da equação de Penman-Monteith, de 
medidas lisimétricas e de equações empíricas. 2002. $103 \mathrm{f}$. Tese (Doutorado em Agronomia) - Universidade de São Paulo, SP.

MOUHOUCHE, B. et al. Effects of water stress applied at different phenological phase on yield components of dwarf bean (Phaseolus vulgaris L.). Agronomie, v.18, p.197-205, 1998.

SILVEIRA, P.M.; STONE, L.F. Manejo da irrigação do feijoeiro. Santo Antônio de Goiás: Embrapa Arroz e Feijão, 2002. 4p. (Circular técnica, 38).

STONE, L.F. Irrigação do feijoeiro e do arroz de terras altas no sistema plantio direto. Revista Plantio Direto, v.14. p.3134, 2005.
STONE, L.F.; MOREIRA, J.A.A. Efeitos do sistema de preparo do solo no uso da água e na produtividade do feijoeiro. Pesquisa Agropecuária Brasileira, v.35, p.835-841, 2000. Disponível em: $<$ http://www.scielo.br/scielo.php?script=sci_arttext\&pid=S0100204X2000000400022\&lng=en\&nrm=iso\&tlng=pt $>$. doi: 10.1590/ S0100-204X2000000400022.

VAN GENUCHTEN, M.T. A closed form equation for predicting the hydraulic conductivity of unsaturated soils. Soil Science Society of America Journal, v.44, p.892-898, 1980.

WUTKE, E.B. et al. Propriedades do solo e o sistema radicular do feijoeiro irrigado em rotação de culturas. Revista Brasileira de Ciência do Solo, v.24, p.621-633, 2000. 